УДК 811.161

Г. В. Токарев

\title{
ВОПРОСЫ ОПИСАНИЯ МАКРОСТРУКТУР СЛОВАРНОГО СОСТАВА
}

Токарев Г. В. Питання опису макроструктур словникового складу.

У статті розглянуто підходи до опису лексичного складу. Проаналізовано принципи наукової та наївної категоризації. Витлумачено лексико-семантичну категорію. 3'ясовано сутність семантичних відношень, які організовують великі групи слів.

Ключові слова: лексикологія, значення, парадигматика, синтагматика, категоризація, класи слів, лексико-семантичні поля. 
Токарев Г. В. Вопросы описания макроструктур словарного состава.

В статье исследуются подходы к описанию лексического состава. Анализируются принципы научной и наивной категоризации. Даётся толкование лексико-семантической категории. Рассматривается сущность семантических отношений, организующих большие группы слов.

Ключевые слова: лексикология, значение, парадигматика, синтагматика, категоризация, классы слов, лексико-семантические поля.

Tokarev G. V. Questions descriptions macrostructures vocabulary.

The article discusses approaches to the description of lexical structure. Discusses the principles of scientific and naive categorization. Interprets the lexical-semantic category. The essence of the semantic relations, organizing large groups of words.

Key words: lexicology, the value paradigms, syntagmatics, categorization, word classes, lexical and semantic fields.

Категоризация - сложный процесс познавательной деятельности человека, который включает в себя (a) образование категорий, (б) соотнесение со сформированными категориями новых знаний об устройстве мира, (в) классификацию языковых единиц, обозначающих эти знания. Под категорией следует понимать языковые группы элементов, выделяемые на основании того или иного признака (признаков), общности функций.

Существует несколько подходов к пониманию сущности категоризации.

1. Традиционными являются учения, восходящие к трудам Аристотеля и Платона. Сущность этого подхода заключается в том, что все единицы, входящие в ту или иную категорию, должны обладать одинаковым набором существенных признаков, иметь тождественный статус в процессе категоризации. Данный подход осуществляется при составлении той или иной классификации. Например, семантическая классификация лексики предполагает наличие у всех элементов, образующих категорию, общей архисемы и одной или нескольких одинаковых дифференциальных сем в зависимости от уровня классификации. Так, терминологию самоварного промысла можно разделить на восемь групп: наименования технологических процессов и операций, инструментов, дефектов, материалов, видов продукции, профессий, приспособлений, инструментов. Каждая из указанных групп выделяется на основании общности архисемы, которая обозначена в названии лексической совокупности. Лексико-семантическая группа «Инструменты» имеет три уровня классификации. Каждая подгруппа включает в свой состав термины, дефиниции которых обладают общей дифференциальной 
семой, соответствующей тому или иному уровню классификации.

1-й уровень. Общая дифференциальная сема 'обрабатываемый материал': деревообрабатывающий / металлообрабатывающий инструмент.

2-й уровень в группе «Металлообрабатывающий инструмент». Общая дифференциальная сема 'функция инструмента': крепёжный, чистящий, сверлильный, раскроечный, гибочный, режущий, отделочный инструмент.

3-й уровень в группе «Отделочный инструмент». Общая дифференциальная сема 'молоток': выемочный, кубовой, ленточный, отливной молотки, наводильник ('самоварный восьмигранный молоток, которым оттягивают стенки самовара'), киянка ('деревянный молоток').

2. Другой подход основывается на трудах Л. фон Витгенштейна. В науке этот подход получил название теории фамильного (семейного) сходства. Сущность этой теории заключается в том, что тождественные признаки могут встречаться не у всех членов категории, а лишь у некоторых, причём набор признаков может варьироваться. Прототипом этой категории стали признаки членов одной человеческой семьи: одни родственники имеют общие черты характера, другие - внешнего сходства и т. п. Учение Л. фон Витгенштейна дало импульс развитию теории прототипов, представленной, в частности, в трудах Э. Рош.

Результаты процесса категоризации при данном подходе можно распределить по трём уровням: суперординатному (наиболее высокому, абстрактному, указывающему на родовые понятия), базисному и субординатному (включающему единицы, детально характеризующие отдельные стороны какого-либо явления или именующие неактуальные объекты действительности). Наибольший интерес представляют те единицы, которые являются составляющими базисного уровня. Единицы, входящие в базисный уровень, называют прототипами. Прототип - привилегированный член, лучший образец той или иной категории, в наиболее полной форме отвечающий сути явления, проявляющий наилучшим образом свойства, характерные и для других её членов. Вокруг него группируются все остальные представители категории. Статус прототипа всегда культурно значим, поскольку прототипы отражают стереотипы, функционирующие в той или иной лингвокультурной общности. Например, в английском языке прототипом птицы выступает малиновка, в русском - ворона. 
Классическая теория наилучшим образом отражает процессы научной категоризации, прототипическая - наивной.

Результатом лексической категоризации являются классы слов.

Классы слов - это большие лексические группы, в основе которых лежит какой-либо интегральный признак. В зависимости от характера этого признака выделяют следующие классы слов:

1) формальные;

2) семантические;

3) формально-семантические.

Формальные классы объединяют слова с общими формальными признаками. Эти слова не имеют общих признаков в значении. Примерами таких классов могут быть глаголы первого спряжения, существительные второго склонения.

Семантические классы слов (семантические поля) объединяют слова, которые имеют интегральные семантические признаки. Например, глаголы движения, названия продуктов питания, термины родства и др.

Формально-семантический класс слов включает слова, сходные как по форме, так и по содержанию. Примерами таких классов могут быть части речи, гнёзда однокоренных слов, слова с одинаковыми словообразующими аффиксами, например, с суффиксом -тель, обозначающим лицо.

Формальные и формально-семантические классы слов изучаются грамматикой, семантические классы слов - лексикологией.

Лексика представляет собой совокупность частных подсистем, которые называются семантическими классами, или лексикосемантическими полями. Внутри этих полей слова связаны парадигматическими отношениями. Основателем теории семантического поля считается немецкий учёный И. Трир. Согласно этой теории, каждая система понятий и представлений репрезентируется соответствующим лексико-семантическим полем. Любой лексико-семантический вариант формирует свою семему в составе поля. Единицы одного лексико-семантического поля имеют тождественные семы.

Семантическое поле обладает следующими свойствами:

1) наличием системных семантических отношений между составляющими;

2) выделимостью из общего семантического пространства;

3) связями с другими семантическими полями, что способствует 
формированию непрерывного семантического континуума.

Приведём несколько примеров семантических полей: «Фауна», «Спорт», «Образование» и т.п. Лексико-семантические поля называют ещё тематическими группами, поскольку в них входят слова одной темы. В лексико-семантическое поле входят слова разных частей речи.

Лексико-семантическое поле состоит из лексико-семантических групп, в которые входят слова одной части речи, имеющие тождественную архисему. Например, тематическую группу «Образование» составляют такие лексико-семантические группы, как «Виды учебных дисциплин», «Учебные заведения», «Субъекты образовательного процесса» и т.п. Слова одной лексикосемантической группы имеют одинаковые парадигматические и синтагматические характеристики.

Сp.:

ученик объясняет, спрашивает

икольник учитель/преподаватель/наставник студент

Дифференциальные семы этих значений являются однотипными.

Автобус - 'многоместный автомобиль для перевозки пассажиров'.

Трамвай - 'поезд (следовательно многоместный) городской наземной железной дороги для перевозки пассажиров’.

Как видим, значения отличаются типовой семой 'способ перевозки'.

Полевой характер тематической группы определяет её структуру. В тематической группе можно выделить центр поля и периферию. Опорное слово в центре поля называется ключевым словом. Для ключевых слов характерна широкая экстенсиональность (объём значения), общеупотребительность, частотность, свободная сочетаемость. Ключевые слова первыми приходят на ум. Адекватная форма репрезентации ключевых слов - абстрактное существительное. Оно, ввиду своей семантической нечёткости, обусловленной тем, что соотносится со слабым, не указывающим на реально существующий предмет референтом, наиболее ёмко репрезентирует те или иные смыслы. Так, к ключевым словам семантического поля «Труд» мы относим труд, работа, дело, поскольку они удовлетворяют психологическому критерию выделения подобных знаков (первыми 
приходят на ум), имеют широкую экстенсиональность, общеупотребительность, частотность, широкую сочетаемость.

Число единиц в лексико-семантическом поле обусловлено культурными факторами. Так, в эскимосском языке много названий снега, в китайском - риса. Русский язык является самым эмоциональным языком в мире. Он включает самое большое количество слов, выражающих эмоции.

В лексико-семантическом поле можно наблюдать все основные виды отношений: парадигматические и синтагматические. Синтагматические связи проявляются в словосочетаниях и предложениях. Эти связи отражают отношения и зависимости между явлениями окружающего мира.

Парадигматические связи охватывают взаимозаменяемые единицы.

Типы лексико-семантических отношений могут быть определены как лексико-семантические категории, выделяемые на основе единства типового лексического значения, соответствующих форм выражения, функций, которые свойственны единицам, подводимым под эту категорию. К лексико-семантическим категориям можно отнести полисемию, синонимию, антонимию, конверсию. Укажем специфические особенности каждой категории.

Полисемия характеризуется связанностью семем одного слова, тождеством плана выражения. Конверсия - связанностью значений единиц, неодинаковостью лексем, способностью выражать обратные действия. Синонимия характеризуется связанностью значений её единиц, неодинаковостью лексем, неспособностью выражать обратные действия, не отрицающими друг друга значениями. Антонимия характеризуется связанностью значений её единиц, неодинаковостью лексем, способностью выражать взаимоотрицающие семемы.

Перечисленные отношения образуют семантические макроструктуры словаря. Значение слова в той или иной степени обусловлено отношениями, в которые оно вступает с другими словами. Для обозначения значения слова в системе языка Ф. де Соссюр предложил термин значимость. Значимость того или иного лексико-семантического варианта указывает на его место в лексической системе, на противопоставленность другому. Таким образом, значимость является элементом значения слова. Иногда термин значимость заменяется на синоним структурное значение. Так, 
возникшее в конце ХX века слово бизнесвумен, имеющее фиксированный состав сем: ‘женщина', ‘бизнесмен', ‘деловая' и др., на основании типизированных семантических отношений (полное или относительное тождество; род - вид и др.), функций сформировало синонимическую: бизнесвумен - бизнеследи; бизнесменка, бизнесмениа; антонимическую: бизнесвумен - бизнесмен; бизнесвумен - домохозяйка - категории.

К семантическим отношениям, организующим семантическое поле, можно отнести отношения:

1) части и целого;

2) родо-видовые;

3) ассоциативные;

4) семантической производности.

Родо-видовые отношения являются главным фактором упорядочивания словаря. Они отражают традиционную, научную категоризацию на основе существенных признаков. Данные отношения представляют словарь как целостную иерархическую структуру. Слово с родовым значением называется гиперонимом. Слово с видовым значением называется гипонимом. Гипонимы, находящиеся на одном уровне членения, называются эквонимами. Так, слово фрукт является гиперонимом. Слова яблоко, груша, сливагипонимы. Между собой они вступают в эквонимические отношения. Значения эквонимов обязательно имеют одинаковую архисему. Экстенсионал (объём значения) гипонимов включается в экстенсионал гиперонима. Родо-видовые отношения отражают уровни сходств и различий явлений.

Партитивные отношения объективируют иерархию связей вещей. Основанием этих связей является целостность мира в его членениях. Слово, именующее целое, называется холонимом: cmул, часть - партонимом: ножка, спинка, сиденье. Партитивные отношения могут быть органическими и неорганическими (механистическими). В органической системе свойства частей определяются свойствами целого. Целое является условием существования части. Ср.: голова часть тела человека, хвост - часть тела животного. Неорганические целые представляют собой множества вещей со свободной структурой. Зависимости частей от целого не столь жёстки. Части не являются условием существования целого. Например, кресло гарнитур.

Партитивные отношения могут быть многоступенчатыми. Ср.: 
университет - факультет - курс - группа и т.д. Уровням обобщения в гипонимии соответствуют уровни цельности в партонимии. В некоторых случаях гипонимическое и партонимическое членения совпадают. Например, мебель - виды мебели, которые являются в то же время частями гарнитура.

При выборе из двух возможных классификаций мышление отдаёт предпочтение гипонимической. Стул определяется как вид мебели для сидения, а не как часть мебельного набора, служащая для сидения.

Отношения семантической производности устанавливаются между единицами поля, связанными отношениями семантической деривации. Обычно эти слова находятся в отношениях словообразовательной производности: мечтать $\rightarrow$ мечтатель, вод $a \rightarrow$ подводник, но не всегда, формальная близость может отсутствовать: писать $\rightarrow$ ручка, пилить $\rightarrow$ ножовка, слушать $\rightarrow$ радио.

Ассоциативные отношения выявляются между словами в результате психолингвистического эксперимента: испытуемый называет все слова, которые ему приходят на ум в связи со словомстимулом. Слова-реакции объективируют коннотации слова-стимула. Например, работать - дурак. Коннотации могут быть не только узуальными, но и индивидуальными. Например, котёнок - подруга.

Изучение семантических полей осуществляется тезаурусным методом. Этот метод был создан в рамках идеографического словаря англичанина Р. Роже (1852). Словарь Р. Роже представляет собой собрание слов английского языка, сгруппированных в шесть крупных тематических категорий, которые разделяются на подклассы. Тезаурус снабжён указателем, в котором все включённые в него слова расположены в алфавитном порядке, и каждому слову приписаны номера тематических групп, в которые оно входит. Таким образом, тезаурус - это система семантических полей. Одно и то же слово может входить в несколько классов тезауруса, поскольку оно может быть связано с разными понятийными сферами. Например, слово переговоры входит в словаре Ю. Караулова в подгруппу «Язык» и подгруппу «Посредничество».

Словарь-тезаурус имеет 4 входа:

1) от концепта к концепту. Причём концепты связаны гиперогипонимическими отношениями. Родо-видовая иерархия словаря называется его синоптической схемой;

2) от концепта к знаку, его обозначающему;

3) от знака к концепту, который он обозначает; 
4) от знака к знаку, то есть указание на связи и отношения между словами.

\section{Литература}

1. Болдырев Н. Н. Когнитивная семантика : Курс лекций / Н. Н. Болдырев.Тамбов : Изд-во Тамбов. гос. ун-та, 2001. - 123 с.

2. Кобозева И. М. Лингвистическая семантика / И. М. Кобозева. - М. : МГУ, 2000. $352 \mathrm{c}$.

3. Никитин М. В. Основы лингвистической теории значения / М. В. Никитин. М. : Научный центр проблем диалога, 1988. - 757 с.

4. Новиков Л. А. Семантика русского языка / Л. А. Новиков. - М. : Высшая школа, 1982. - 272 с. 